\title{
LOS “CHAVOS-BANDA” y LA PENDENCIA
}

José Luis Flores Reyes Servicios Educativos Integrados del Estado de México

\section{INTRODUCCIÓN}

Donde hay vida hay cambio, y donde hay cambio subsiste el conflicto. Como afirma Dahrendorf "Toda vida social es conflicto, porque es cambio. No hay en la sociedad humana algo estable, porque no hay nada cierto".

El conflicto social comprende "...todas las relaciones contrarias, originadas estructuralmente, de normas y expectativas, instituciones y grupos"2 $\mathrm{Su}$ presencia muestra las perspectivas de contrarrestar las fuerzas de un antagonista o bien, de lesionarlo estropeando sus intereses y, en el último de los casos, descartándolo en una lucha abierta para suprimirle toda intención permanente de expresar su antagonismo.

Sin embargo, como advierte Dahrendorf, “...no es preciso que estos conflictos sean siempre violentos. Pueden presentarse de un modo latente o manifiesto, pacífico o violento, suave o intenso". ${ }^{3}$

Bajo estas premisas intentaremos analizar la diversa manifestación conflictiva de un grupo de jóvenes denominado la banda de "Los Pancheros", que existió en el barrio del "Cóporo" de 1984 a finales de 1987.

Para el anterior objetivo se analiza dicho grupo social en relación a grupos y/o símbolos antagonistas a él. Se eligieron; por ello, la policía, otras bandas, y partidos políticos. Por ello, para escudriñar dichas manifestaciones conflictivas, es pertinente observar a estas unidades concretas y su relación conflictiva bajo la óptica de Coser. ${ }^{4}$

1 Dahrendorf, Ralf. Sociedad y libertad. Tecnos, Madrid s/f. pág. 208.

2 Op.cit. pág. 119.

3 Ibidem. pág. 119.

4 Coser, Lewis A. Las funciones del conflicto social. F.C.E. México 1961. 


\section{LA BANDA Y LA POLICÍA}

La cotidianidad de "Los Pancheros" se encuentra revestida por la presencia de diversos antagonismos, entre ellos con cuerpos policiacos. Esta figura ha impuesto y contribuido a la formación de una estructura interna de redes de cooperación dentro de la banda.

"Este mira las bandas aqui existen sabes por qué, porque pus es hacer una reunioncita aqui entre todos los compas pus es buena onda, también pus como punto de represión ¿no? a nuestra forma de vivir ¿no? este en contra de las autoridades ¿no?. Las autoridades no agarran el punto de nuestra acción ¿si?.. Estamos muy mal toda la sociedad ¿no? entonces las bandas por eso salen cabrón como una forma de mitigar sus sufrimientos."

"Los Pancheros" manifiestan su espontaneidad cotidiana en la calle de Manuel Alas. En grupo, al caer la noche, se desplazan al "Capri”, a los cines Rex, Florida y en ocasiones al teatro Morelos de la ciudad de Toluca. Otras veces se reúnen en la ex-Concha Acústica, o bien con desmanes se encaminan por las calles de Bravo Norte para llegar a la Iglesia de "Cristo Rey".

Este suceso provoca desconcierto en las personas ajenas, así como del mismo barrio, ya que al toparse con la banda piensan que pueden ser agredidos. Y en efecto, en ciertas ocasiones la banda llega a agredirlas luego de que les piden dinero y, al rehusarse insultantemente, provoca una ofensa que se resuelve con agresividad.

La policía, a petición de los vecinos, interviene para reprimir a "Los Pancheros", con lo que la propensión del antagonismo entre ambos comienza a canalizarse por la aparición de un conflicto inofensivo que se inclinará hasta su más fina violencia.

Las redadas y razzias sobre la banda "Los Pancheros" no se hacen esperar. En recorrido de cinco patrullas en el barrio, a determinadas horas del día y principalmente de la noche, los "Chavos-banda" son detenidos y remitidos a la delegación policial correspondiente.

Entonces la banda tiene que pagar multas para poder salir de la cárcel municipal, aunque otras veces utiliza el soborno para regular las redadas que se van acumulando. Este es el momento en que la banda muestra sus redes de solidaridad:

“... a veces si nos agarran a dos cuatro, a veces hasta diez ¿no?, los demás a veces que es lo que hacen, tratan de juntar un dinero ¿no? para qué, para sacar a unos CUantos. Enton 's los que salen tratan de juntar también dinero para los demás... nosotros siempre nos apoyamos siempre..." "6

5 Entrevista a "Los Pancheros".

6 Entrevista a "Los Pancheros". 
Ante esta acometida de los cuerpos policiacos, la banda crea una identidad propia, una frontera hacia el exterior con una socialización íntima. Como atestigua Coser "La distinción entre 'nosotros, nuestro grupo o el grupo intrínseco, y todos los demás, los otros grupos o grupos externos’ se establecen en el conflicto y por el conflicto"?

La solidaridad intrabanda se expresa, en primera instancia, ante los actos policiacos, los cuales acusan a la banda de ser traficantes de drogas.

La presencia de la banda en su territorio a altas horas de la noche revive el motivo para el arresto fundamentado con dicha denuncia

"...cuando simplemente nos han agarrado siempre nos han dicho: ustedes son de allá arriba ¿verdad? de los macizos, de los que distribuyen droga... simplemente pasan dos tres patrullas por Bravo y qué es lo que hacen !bunuy! ya están atizando, a lo mejor están otra cosa, vamos a subir y los agarramos, y qué es lo que hacen sacar más dinero ¿ves? Pero nosotros decimos!no! pos estamos aqui cotorreando... ".

Los sobornos y el pago de multas son el medio del que se sirve la banda para regular el conflicto9 con la policía; sin embargo, éste medio no tiene la eficacia para apaciguar totalmente el antagonismo. Las reprimendas hacia "Los Pancheros" se agudizan y la hostilidad hacia los cuerpos policiacos se hace más patente.

"Los Pancheros" etiquetan a la policía como su antagonista principal, ya que al encontrarse en fiestas dentro o fuera del barrio, los "Chavos-banda" son aprehendidos con lujo de violencia por sospechosos. "Les decimos el motivo de dónde venimos y todo eso, iino ni madres!! ustedes son sospechosos y súbanse, y si no, nos subimos a garrotazos o pinches cachazos...la autoridad ya sea municipal o judicial, o cuerpos policiacos especiales..."

Ante la agresión policiaca, la banda responde de la misma manera, se reordena internamente para buscar solución al conflicto, lo cual pone en peligro su integración. La cohesión reforzada en "Los Pancheros" define la intensidad del conflicto con la policía "...la estructura del grupo ayuda a definir la intensidad, actual o prevista, del conflicto con el exterior...."

La banda, en este contexto, muestra perturbación, intranquilidad, y los mismos intereses que muestran los "Chavos-banda" para mantener la existen-

7 Coser, Lewis A. Las funciones... op.cit. pág. 37.

8 Entrevista a "Los Pancheros".

9 "Los conflictos que surgen de la frustración de demandas especificas dentro del marco de relaciones, y de la estimación sobre las ganancias que los participantes pueden lograr, y que benefician al presunto objeto frustrador, pueden llamarse conflictos reales, en cuanto son medios para lograr un resultado específico". Véase Coser, Lewis A. Las funciones... op. cit... pág. 55.

10 Entrevista a "Los Pancheros".

11 Coser, Lewis A. Las funciones... op.cit. pág. 117. 
cia de "Los Pancheros" los incita a involucrar su individualidad e intimidad al interior de la banda. De esa manera se busca solucionar el conflicto, divergencia que se tiende a derrumbar bajo el consenso intrabanda:

“...son cuerpospoliciacos que nos reprimen grueso, entonces de esa forma también accedemos a esa situación; aunque salgamos victoriosos o no salgamos victoriosos pero ora sí no nos vamos a dejar ¿no?..porque pus ya hemos tenido enfrentamientos aqui que olvidate ¿no?”. ${ }^{12}$

En ese sentido el conflicto con la policía solidariza, integra y vincula la personalidad ${ }^{13}$ de los "Chavos- banda" hacia el interior de la banda misma. La objetivación del conflicto extiende, en la estructura interbanda, una inclinación de los "Chavos-banda" por representar en la gresca un interés grupal de asestar sus objetivos de lucha para la sobrevivencia de la banda. Como afirma Coser "El conflicto comunal...el basado en una aceptación común de los objetivos fundamentales, es...integrador. Cuando los hombres saldan sus diferencias sobre la base de la unidad, sobrevendrá un conflicto comunal”." ${ }^{14}$

El conflicto, evidentemente real, comienza a mostrar su grado y su ambiente genérico. La aparición de la agresión contra el objeto de hostilidad, es decir la policía, es complemento de la controversia. Además se hace más violenta y contribuye a la liberación de tensiones insoslayables manifiestas, sin que esto implique que deje de ser un conflicto real.

No es ineludible que el conflicto entre la banda y la policía esté vinculado sólo a la agresividad, debido a que existen otros medios sosegados subyacentes para solucionar la controversia entre ambos. "El conflicto real no va necesariamente acompañado de hostilidad o agresividad", ${ }^{15}$ sin embargo dado que la banda es un grupo cerrado y militante, donde sus integrantes concentran toda su personalidad, el aumento de la virulencia del conflicto condiciona la detallada organización de "Los Pancheros" y el incremento de la violencia. Esto es: a mayor virulencia del conflicto, mayor organización de la banda y en consecuencia mayor utilización de la violencia.

El aumento de la virulencia del conflicto de "Los Pancheros" hacia la policía explica el incremento de su organización y del uso de la violencia en la lucha. La meta colectiva que prescinde de todo interés subjetivo, desligada del carácter individual que afectan a los valores de la banda en su conjunto, marcan los principios y reglas que al interior de la banda se asocian de manera impersonal y objetiva que, ligada a la creciente intensidad del conflicto, dan pauta al surgimiento de una mayor organización interna.

12 Entrevista a "Los Pancheros".

13 Véase Coser, Lewis A. Las funciones... op.cit. pág. 77.

14 Op.cit. pág. 84-85.

15 Ibídem. pág. 68. 
En su carácter de grupo cerrado, la banda participa con toda la personalidad e intimidad de sus miembros por la causa e interés de lucha por responder a la agresión policiaca. Así, la solidaridad intrabanda evidencia en su estructura una organización que al momento del estallido violento del conflicto con la policía, legitima la concentración de todas sus fuerzas en la defensa por la supervivencia de la banda.

La agrupación de toda la voluntad y fuerza de la banda, ante la presencia del conflicto que legitima dicho interés colectivo, revela la objetividad del conflicto.

En efecto, la lucha contra los cuerpos policiacos establece para la sobrevivencia de la banda un sin fin de expresiones que muestran dicho interés colectivo. Todo "Chavo-banda" cuenta con intereses y perspectivas distintas a las de su semejante dentro de la banda, y sin embargo para mantener la existencia de "Los Pancheros" el mecanismo es desaparecer dichas diferencias creando un consenso interno:

"... es por eso que nunca nos dejaremos, te digo nosotros cuando un morro se quiere unir a la banda o que ya está en ella, lo único que le hemos dicho sabes qué? lo único que queremos es que tú seas de güevo ¿no? la verdad; no nos importa que nos vengas a presumir no nos importa, simplemente hay que ser, te lo vuelvo a decir de güevos ¿no?"16

"La lucha por una causa supraindividual, despoja de intereses y deseos individuales (y por tanto discrepantes), fija la atención sobre el fin inmediato y concentra todas la fuerzas para actuar en un solo sentido. Los individuos imbuidos de la idea de que 'representan' o encarnan los objetivos del grupo estarán más dispuestos a responder a requerimientos impersonales." ${ }^{\text {"I }}$

En el desarrollo del conflicto banda-policía existe un punto de referencia que consiste en alcanzar una meta específica (colectiva), basada en el consenso por cada uno de los contendientes; la aparición del conflicto abierto como medio para lograr el objetivo de destruir a su antagonista está definido por su eficacia dada la virulencia de la rivalidad; es decir, la lucha está condicionada por razones culturales ${ }^{18}$ así como por la misma estructura de los contendientes que se muestran como grupos cerrados.

El conflicto entre la banda y la policía no muestra el carácter institucional que todo conflicto contiene. Como afirma Coser "...el conflicto no solo implica un punto común de referencia y la aceptación de reglas comunes... sino también una meta común" ${ }^{19}$. En a objetivación del combate no hay reglas

16 Entrevista a "Los Pancheros".

17 Coser, Lewis A. Las funciones... op.cit. pág. 132.

18 Véase, Salazar, Francisco. Reflexiones en torno al concepto de cultura. UAM-A. Mimeo s/f. pág. 14.

19 Coser, Lewis A. Las funciones... op.cit. pág. 135-136. 
que guíen la manera de cómo se conducirá la contienda, No existen alternativas que simbolicen su elemento limitado, como en el caso de las bandas y la policía de la Ciudad de México ${ }^{20}$ que buscan entablar un diálogo para encontrar solución inmediata al conflicto.

El conflicto se vuelve absoluto e ilimitado, carente de poder crear un aliciente entre ambos antagonistas. El conflicto tiende a la liquidación total de la banda "Los Pancheros", buscando su desintegración, ya que en el conflicto absoluto "...la meta es la destrucción final del enemigo y no un arreglo mutuamente convenido...." 21

En consecuencia, no hay una reciprocidad sino una imposición en los resultados basados en las relaciones de poder de la estructura más poderosa sobre la más endeble. El triunfo de la policía sobre la banda es, ciertamente, fugaz y efímero; se precisa renovar día con día en un círculo interminable y vicioso.

\section{LA BANDA Y LAS BANDAS}

La distinción de el conflicto entre la banda de "Los Pancheros" y las bandas de "Los Malditos" y "Lucas", subsiste bajo la condición de la emulación y el resentimiento hacia la banda del Cóporo y viceversa, es decir, bajo la disposición del conflicto irreal y real respectivamente.

Este suceso muestra la presencia de sentimientos hostiles que se acumulan o expresan en la medida que las bandas se encuentran en fiestas en sus barrios o en otros lugares. El deseo por la competencia entre los mismos "Chavos-banda", por incrementar su superioridad hacia el exterior, implica y demuestra la presencia de un conflicto.

"Muchas bandas nos odian ¿no? en la manera de bailar ¿no?, y en la manera de vestirse $y$ de accionar ¿no?, simplemente nuestros cotorreos simplemente. Dos tres bandas han quedado ay ¿no? son 'Los Pancheros' siempre ¿no? 'Los Pancheros' y a veces vamos otra vez a, ese barrio ¿no? y te dicen ora que vengan 'Los Pancheros' los vamos a madrear, pero nunca se les ha hecho". ${ }^{22}$

20 Véase, Revista Encuentro de la Juventud, Mayo de 1986 núm. 28. CREA, México. pág. 20-21.

21 Coser, Lewis A. "La terminación del conflicto” en: Etzioni, Amitai y Eva, compiladoras. Los cambios sociales. Fuentes, tipos y consecuencias. F.C.E. 1984. pág. 419.

22 Entrevista a "los Pancheros". 
El conflicto ha sido creado por la emulación, donde la banda de "Los Pancheros" actúa como grupo de referencia positivo ${ }^{23}$ frente a las otras bandas, las cuales vierten sentimientos hostiles provocando así una rivalidad intensiva a pesar de su profundo antagonismo.

La contienda inofensiva (competencia por demostrar quién baila, viste o acciona como banda) entre "Pancheros" y bandas como "Los Malditos" y "Lucas" llevadas a cabo regularmente en el salón de baile "Capri”, desecha la posibilidad de hallar y obtener el dominio sobre alguna de ellas.

La emulación funciona como un mecanismo substitutivo por el cual el antagonismo abierto no llega a producirse. Solamente hay una liberación de tensiones que tiene como finalidad mantener la continuidad de las relaciones tradicionales interbanda.

Entre las bandas, el consumo de alcohol y droga y las alianzas para divertirse conjuntamente es efímera, ya que la prolongación de la rivalidad es evidente luego de que el conflicto no transforma las relaciones sociales entre los "Chavos-banda". Como afirma Coser "Mientras que el conflicto modifica los términos de la interacción, la simple expresión de los sentimientos hostiles no lo hace". ${ }^{24}$

La manifestación del conflicto es cambiante en cuanto a su objeto. Quien viste, baila o “acciona” mejor, son válvulas de escape sobre las cuales su odio acumulado es apaciguado y, relajada toda la tensión, se aglomera en creciente rivalidad interbanda, negándose a buscar un objetivo concreto para dominar a una u otra banda, y solo provoca la simple descarga de enemistad que acarrea dicha competencia o rivalidad (emulación).

"No, la verdad no, y es lo que hemos tratado de hacer, de que nadie de nosotros llegue hasta cierto punto de que esté en agonía y ya no ¿ves?, sino simplemente todos nos cuidamos y nunca queremos que llegue a pasar eso entre la banda." ${ }^{25}$

En este proceso de emulación no existe una interacción entre estos agentes frustrantes, ya que no se revela una agresión palpable entre las bandas. La acometida es encubierta y revestida por una causa ilimitada ante la figura absoluta del conflicto, carente de reglas y costumbres, para determinar un vencido y un vencedor. ${ }^{26}$

No se proporcionan símbolos culturales propios de las bandas para identificar tal virtud y apoderarse del lugar en disputa, para realizar su esponta-

23 Coser, Lewis A. Las funciones... op.cit. pág. 102

24 Op. cit. pág. 49.

25 Entrevista realizada a "Los Pancheros".

26 Véase, Etzioni, Amitai, et. al. Los cambios sociales... op. cit. pág. 419-423. 
neidad cotidiana. Todo es conducido por la ramplona inercia. No se busca un resultado concreto, sólo se quiere derramar hostilidad, lo que puede provocar el acaecimiento de un conflicto.

En consecuencia la hostilidad se agudiza o se mantiene hasta llegar a crear una explosión interbanda que tienda a un enfrentamiento catastrófico como lo prevé la misma banda.

"...hemos tenido conflictos con otras bandas ¿no? y la verdad si, y se ha hecho en grande ¿no? y hasta hemos pensado llegar a lo más grande ¿no? hacer bombas y haciendo llamas de fuego ¿no?, pero simplemente no nos provoquen porque si nos provocan la verdad siempre, siempre estaremos fletados.".

Y efectivamente, como afirma Coser, “...las instituciones que solo sirven para descargar los sentimientos de hostilidad, y dejan sin modificar los términos de la relación, pueden operar como pararrayos, pero no pueden impedir una periódica acumulación de nubes, es decir, una nueva acumulación de tensiones". 28

El conflicto reconocido a través de la emulación interbanda puede valorarse como irreal en cuanto se convierte en un fin para descargar las tensiones de la hostilidad, sin perseguir el objetivo de dominio de una banda sobre otra.

El desplazamiento de los medios para aliviar las tensiones es fortuito, y se concentran en demostrar qué banda viste más extravagantemente, cuál baila y acciona como banda rockera.

"Nosotros estamos concernientes y conscientes en que nos gusta el rock ¿isi?, acudimos a tocadas de rock ¿si? a cualquier salón acá chido ¿no? y seguimos nuestra onda; vestimos de mezclilla, chamarra de cuero ¿si?, pantalón aguado ¿si?..pero asi nos gusta vestir cabrón ¿si? tenis acá ¿no?."29

Por ello el conflicto no llega a producirse directa- mente, ya que es paliado por los medios inofensivos e indirectos, substitutivos en relación a la lucha por el destino de las bandas respecto a su relación de poder y dominación entre ellas. Este tipo de relación únicamente lleva a estabilizar las relaciones interbandas, pero con una tendencia siempre creciente a desatar una nueva situación de conflicto con nuevos matices y características singulares.

"Nosotros teniamos primero unos conflictos ¿no? con una banda de las Peñas ¿no?, que

'Los Malditos'y la retama, que 'Lucas'y eran, siempre fueron nuestros rivales ¿no? pero

27 Entrevista realizada a "Los Pancheros".

28 Coser, Lewis A. Las funciones... op.cit. pág. 53.

29 Entrevista realizada a "Los Pancheros". 
ya se dieron cuenta 'Los Malditos' que la verdad no pudieron con nosotros ¿no? y ahora la única banda rival que nos queda es de Lucas Alamán, la banda 'Lucas' y por eso nunca nos dejaremos... ". 30

El resentimiento en la emulación como función latente, además de conducir a una acumulación de hostilidades en las relaciones entre las bandas de "Los Pancheros", "Malditos" y "Lucas", ha guiado a que esas relaciones tengan una función manifiesta en el conflicto mismo. La lucha en un barrio por apoderarse de una esquina o el enfrentamiento para ocupar la ex-Concha Acústica de los portales de la Ciudad de Toluca, son muestras de una lucha de poder que subyace en la agresión directa para imponer y preservar un domino del lugar y de las relaciones interbandas, mismas que determinan el destino de su legitimidad e identidad así como su existencia.

La lucha interbanda, como función manifiesta del conflicto, involucra una serie de reglas que generan el mecanismo para identificar al ganador, valorando al que tendrá dominadas las relaciones interbandas.

"Fijate que las rucas del Seminario nos dicen: 'Pos no que 'Los Pancheros' muy chingones, y ya se los apañaron', ¿capeas?; y nel acá la hacemos chida ¿no? andamos por el portal y si se quieren pasar de lanza con nosotros pos acá les damos en su madre."31

Los medios (conflicto) que las bandas utilizan para expresar su hostilidad están determinadas por la lucha abierta, persiguiendo con ello obtener representatividad ante sus rivales, además del dominio estratégico para convivir sin ser molestados aún dentro de sus propios barrios. y aunque la pelea abierta representa el medio más eficaz para lograr su objetivo, se podría pensar que estas bandas tuvieran la alternativa de utilizar otros medios diferentes a los golpes, ya que cuentan con un objetivo concreto sin desatar ingenuamente la lucha para únicamente satisfacer sus sentimientos hostiles.

Sin embargo, los medios pacíficos, como el uso del graffiti para delimitar su territorio, no tendrían la misma contundencia que la lucha abierta. Esta última se selecciona luego de que entre las bandas representa el factor más idóneo para llegar a su objetivo. "La selección de objetivos es fortuita en el nivel psicológico, y no en los niveles cultural y estructural, ya que la idoneidad de los objetivos como medio para aliviar la tensión depende de numerosos factores culturales y estructurales" ${ }^{32} \mathrm{El}$ enfrentamiento directo representa una parte de esa cotidianidad espontánea de los "Chavos-banda”, donde están aglutinados los valores e ideología de la vida inherente a la sociedad.

30 Entrevista realizada a "Los Pancheros".

31 Entrevista realizada a "Los Pancheros".

32 Coser, Lewis A. Las funciones... op, cit, pág. 187. 
Lo esencial de la lucha interbanda subyace en sus reglas una serie de símbolos, para especificar y aclarar quién ha resultado vencedor y quién vencido. Cuando "Los Pancheros" y "Malditos" buscan ocupar las calles que dan acceso a la Iglesia de Cristo Rey, generan una pelea representada por dos "Chavos-banda" (machines) seleccionados por el líder de cada uno de ellos.

Si la gresca individual no es suficiente para determinar un ganador, el combate colectivo no se hace esperar, arrojando a la luz al vencedor. Dentro de ellas se reconocen reglas implícitas durante el enfrentamiento: palos, armas blancas, chacos, cadenas y tubos salen a darle forma. "Es lógico que los conflictos de esta clase -por lo menos entre contendientes de fuerzas aproximadamente iguales- sean sumamente costosos y agotadores. Si los contendientes quieren evitar que la lucha se convierta en un juego definitivo, en que el resultado solo puede ser la derrota total o la victoria total, tienen un interés común en crear mecanismos que puedan llevar a una terminación de la lucha".33

Las bandas se organizan en pequeños comandos para elaborar su ataque y se concentran para formar una gran masa humana que rodea a los involucrados en la gresca. Con sus golpes sobre el contrincante enarbolan la finalidad de ambas organizaciones: el dominio por una esquina, barrio neutral o propio. Al término se obtiene un ganador y un perdedor, status que retornan las bandas para etiquetarse de acuerdo al resultado.

Las condiciones de la lucha determinan las reglas implícitas en los resultados, al mismo tiempo que el lugar donde se desataba el conflicto influye para prescribir el tipo de armas y la manera de encausar el conflicto.

"Pues mira depende ¿no? cómo te salga la banda, porque es cuando suben al barrio suben con dos, tres palos, pus también hay que juntar armas ¿no? porque no hay que dejarse, $y$ de repente si salimos en otras tocadas y estás en unos tiros pues si nos los sacamos, hasta ahi ¿no? pero eso si, muchos se dan cuenta porque a veces nos ven solos y no saben si agarrarnos o no, porque al rato uh, donde nos topemos no se la acaban, la verdad".34

El conflicto encausa a los "Chavos-banda", de manera consciente, a la búsqueda de medios y soluciones viables para responder al acto beligerante que los envuelve su análogo.

Durante el enfrentamiento individual se deben res- petar reglas. Por ejemplo, únicamente dirigir la atención por parte de las bandas sobre sus compañeros en disputa, prescindiendo de una posible intervención masiva. Cuando es violada esta regla, todos se involucran hasta el grado de que una de las bandas salga huyendo para aceptar su derrota no obteniendo la esquina o

33 Etzioni. Amitai, et. al. Los cambios sociales... op.cit. pág. 419.

34 Entrevista realizada a "Los Pancheros". 
dominio sobre su contrincante. Ese es uno de los símbolos interbandas que evidencian al vencedor. Evadir la provocación, el no recurrir los lugares acostumbrados anterior al estallido del conflicto, son otros símbolos que enseñan la aceptación de la derrota.

El uso de las armas en el conflicto se determina implícitamente (como una regla) de acuerdo al grado de hostilidad acumulada anteriormente, ligada al objetivo a perseguir, además del peso de la fuerza que representa cada banda para lograrlo. A mayor intensidad del conflicto, mayor uso de la fuerza; a menor prolongación del conflicto, menor uso de la fuerza.

Estos conflictos interbandas son un medio para conseguir el dominio sobre un territorio o contrincante, conducidos por una lucha de poder a poder.

"Pues mira yo te voy a ser sincero, la verdad en otros barrios sí, tú sabes que todo barrio es ley ¿no? y este, la verdad te voy a ser sincero, nosotros hemos comandado todo Toluca ¿no? la verdad hemos llegado a dos tres municipios donde nos conocen, nos respetan ¿no? y todo Toluca es de nosotros". ${ }^{35}$

Este conflicto social se considera real, ya que cuenta con un objetivo concreto y limitado en relación a los resultados específicos. Como afirma Coser "Cuando más restringido es el objeto de la contienda y cuanto más visibles son para ambas partes los indicios de victoria, mayores son las posibilidades de que el conflicto sea limitado en tiempo y amplitud...." ${ }^{36}$

En el conflicto interbanda se elige toda forma de disputa, es decir, los medios para adquirir un resultado y al mismo tiempo una satisfacción, proceso que tiende a eliminar el conflicto. Además, es limitado dada su precisión en el interés que se persigue en razón de las condiciones cambiantes de dominación subyacentes en la interacción. ${ }^{37}$

La estructura de "Los Pancheros" muestra una socialización creciente a medida que el conflicto con la banda "Lucas" y "Malditos" aumenta. Las variables que dan fe de este proceso son la función latente del conflicto (emulación interbanda) y la función manifiesta (lucha abierta) del mismo.

“... nosotros nos juntamos porque nadie se iría a una fiesta solo la verdad; entonces nos conocemos porque dos, tres, en dos tres tocadas que hemos ido la verdad nos envidian ¿no? porque en nuestra banda todos somos buenos bailarines... y es por eso que varios no bailan $y$ tienen envidia también por eso pero siempre andamos todos juntos y la verdad no bay un lider entre nosotros, simplemente hay que tener much a cabeza"38

35 Entrevista realizada a "Los Pancheros".

36 Etzioni, Amitai y Eva. Los cambios sociales... op. cit. pág. 420.

37 Coser, Lewis A. Las funciones... op. cit. Véase pág. 54 sobre el conflicto real.

38 Entrevista realizada a "Los Pancheros". 
En la banda de "Los Pancheros" no hay una diferenciación de funciones en su estructura en lo que respecta a la función latente del conflicto en contra de la banda de "Los Malditos". Todos los "Chavos-banda" bailan al ritmo de la música; solos o en pareja hacen gala de sus movimientos, con brincos, revolcándose en el piso dando tributo de su espontaneidad cotidiana a la noche obscura. No hay un líder en "Los pancheros" que guíe la forma de bailar, cada uno de ellos elige los movimientos corporales a expresar.

La emulación interbanda se lleva a cabo en los barrios del Cóporo, Santa Bárbara, Retama, el Reflejo y en el salón de fiestas "CAPRI", para ir a bailar la música de Cachareli y Forastero, patentizando así a "Los Pancheros" como un grupo de referencia positivo, ${ }^{39}$ imitándosele, aunque sin éxito, para intentar obtener superioridad sobre ella en este aspecto.

La incitación a la emulación conlleva a poner en incertidumbre los valores de la banda de "Los Pancheros", por lo que tiende a reafirmarlos por medio de una competencia inofensiva donde se descargan algunas tensiones.

Dicha expresión latente de antagonismo, si bien es un aliciente para que no estalle el conflicto, también es cierto que integra y ordena a través de la emulación la estructura de la banda de "Los Pancheros", asimilándose en sus integrantes una cohesión sin la necesidad del advenimiento de un conflicto. Como afirma Coser "...si la estructura social básica es estable, si los valores fundamentales no se ponen en tela de juicio, entonces generalmente la cohesión se refuerza mediante la guerra, invocando y revitalizando valores y metas anteriormente aceptados". ${ }^{40}$

La solidaridad es unánime, el consenso tiene presencia en "Los Pancheros" por lo que no es pertinente la subordinación de sus miembros, la cohesión es inherente a la estructura del grupo.

En la manifestación del conflicto, ${ }^{41}$ es entonces cuando la relación interbanda muestra funciones de referencia negativa ${ }^{42}$ sobre la estructura de "Los Pancheros", incitándolos a la aguda integración de sus propios miembros, los cuales antes de la aparición del conflicto revelaban ya un consenso reflejado en la emulación interbanda, dando prueba de la existencia de su cohesión que ahora se robustece ante la prolongación del peligro externo.

Pero no todo es hostilidad y antagonismo entre "Los Pancheros" y bandas como "Los Malditos" y "Lucas". La función del conflicto también crea alianzas entre ellas además de que hace más intensa su participación en su entorno social.

39 Coser, Lewis A. Las funciones... op. cit. pág. 102.

40 Op. cit. pág. 101.

41 Véase cita 9.

42 Coser, Lewis A. Las funciones... op. cit. pág. 102 
La alianza interbanda no está fundada sólo por la aparición de un enemigo común que atenta contra los intereses de los afectados. Su espontaneidad cotidiana también es digna de semejante alianza. En una "tocada" o fiesta se reúnen para "cotorrear" en conjunto, pues como afirma Coser "No todas las asociaciones se forman con fines conflictivos...No todos los intereses comunes implican conflicto con otros intereses, por ejemplo los grupos de carácter extraprofesional". ${ }^{43}$

Esta cooperación antagónica que expresa intereses comunes entre "Los Pancheros" y otras bandas, contienen una meta común e inmediata a pesar de que la relación interbanda tiene semejanzas culturales. Pero que sólo se unen cuando ven amenazada su existencia o su territorio. Dicha relación sólo los estimula a unirse por convenir a cada una de las bandas.

La alianza tiene representatividad entre ellas, la lucha es más fácil y contundente "...por que cada [banda] se da cuenta de que puede lograr mejor sus fines uniéndose... La unión es la esencia de la organización, y la organización es el gran instrumento para multiplicar la fuerza de un número de unidades desiguales y disímil es, asociadas para un objetivo común". ${ }^{44}$

Esta cooperación antagonista que implica la compatibilidad de determinados intereses comunes pone en evidencia el interés inmediato de la defensa y supervivencia de la(s) banda(s). Como afirman "Los Pancheros"

"...aqui han venido varios vales de otros barrios ¿no? que nos vienen a pedir un paro ¿si? este que acá, que porque ya, ya lo madrearon abi en su propio barrio y que los apantallaron, que aquel compa se sacó un tiro con aquel güey y que se metió el primo y otro compa i no? ya sabrás entonces ya, ya vinieron a ver a "Los Pancheros" ya son conocidos y nos vienen a pedir un paro ¿si? y me cai que tenemos un, hemos hecho un chingo de paros y por hacer ese.

"También vamos hacer otros paros ¡si? en huichila, acá en las secundarias y las prepas cabrón, ¿si? en la prepa cinco allá en San Felipe, uta, olvídate ¿no? acá chingones "Los Pancheros" ¿si? y pus eso lo quiero recalcar acá a toda madre porque me cai que "Los Pancheros" su/arma de accionar es la que le está dando acá representatividad chingona y machin ¿no?”." 55

Durante la coalición se crea una estructura efímera con intereses inmediatos a alcanzar. Se socializan (se confluyen los líderes) para moderar el conflicto y darle pauta a través de su ajuste, estableciendo una armonía interbanda llegando a dominar a su antagonista.

43 Ibídem. pág. 204.

44 Ibídem. pág. 160.

45 Entrevista realizada a "Los Pancheros". 
Los intereses inmediatos sobresalen sobre los secundarios de manera momentánea en cada banda, como afirma Coser, ${ }^{46}$ su diversidad estructural y cultural es relativa pero evidente, luego de que cada banda es heterogénea como la realidad misma.

Es decir, la relativa diversidad en su estructura conlleva a una relativa posibilidad de que difieran sus intereses secundarios. Sin embargo, estos últimos son únicos en cada banda, por lo que las hostilidades y conflictos entre las bandas (a pesar de contar con una similar cultura) se desarrollan cuando se rompe el límite institucional, cultural, que rige relativamente sobre ellas; es decir, una acción que culturalmente no encaja en ellas. El caso de invadir un territorio ajeno es un caso peculiar.

Una vez que la coalición ha cumplido con su objetivo inmediato es imprescindible que desaparezca porque "si la coalición se aparta de esa meta, corre el riesgo de zozobrar al chocar contra rocas de los intereses antagónicos de sus miembros". ${ }^{47}$ No se puede seguir todo el tiempo con la supresión de los intereses secundarios de cada "Chavo-banda" y de cada banda. Su espontaneidad cotidiana le reclama un actuar específico dentro de su hábitat, a pesar de que comparten similares estructuras vinculadas a una cultura que los identifica. Sin embargo, esta cultura es tan compleja que los diferencia como sujetos particulares en la historia humana.

\section{LA BANDA Y LOS PARTIDOS POLÍTICOS}

Los partidos políticos también forman parte de la escena antagónica, en la vida cotidiana, de "Los Pancheros". La experiencia en la banda de este hecho le ha provocado una hostilidad hacia cualquier vínculo con algún partido político así como internamente.

El "Konde" y otros integrantes de la banda pertenecían al Frente Juvenil Revolucionario (FJR) del Pro. En campañas políticas dentro de la Ciudad de Toluca se conducían con "Los Pancheros" para apoyarlos por largas horas del día. Eran largas horas que la banda esperaba para que fueran cumplidas las ofertas de instalárseles canchas deportivas y favorecer sus actividades cotidianas (tocadas de rock, "reventones", reuniones interbandas).

Durante la campaña política del Pro, a "Los Pancheros" lo único que les interesaba era conseguir el beneficio no sólo para ellos, sino también para los grupos populares de entre los cuales se define como parte de ellos.

46 Véase, Coser, Lewis A. Las funciones.. op. cit. pág. 165

47 Ibídem. pág. 166. 
“... 'Los Pancheros 'es una banda ¿no? netamente popular cabrón ¿si? no apoya ni un pinche partido politico ni a ni una asociación sindical a nadie apoya cabrón, nadamás apoya a los jóvenes con inquietudes ya sabes cabrón de nuestra edad ¿si? netamente popular ¿si?, ya sabes ¿no? psss de escasos recursos... ". ${ }^{48}$

El "konde", en su condición de representante, se convierte en el símbolo que lleva en sus manos el objetivo de la banda, el que sostiene vínculos con el exterior en nombre de "Los Pancheros". Como dice Coser con un “...carácter representativo (en aquellos hechos) en que actúa en nombre de la colectividad a que pertenece". 49

Su relación con el (FJR) lo reviste como el "Chavo-banda" más activo dentro y fuera de la banda, lo que tiende a que sea el representante de "Los Pancheros" al vincularse estos últimos con el PRI. Por ello subyacen en él las demandas de la banda, y no porque sea el líder de la misma.

Este representante en un primer momento se transforma en la bandera de las demandas de la banda, el consenso y la autoridad interbanda conjuntamente con las características de grupo cerrado que posee, prescriben los objetivos comunes. La solidaridad hacia el "Konde" se entiende como una inversión que la banda realiza con el fin de prescindir de demandas subjetivas y personalizadas, obedeciendo la lógica de la intimidad de la banda y para la banda.

Ya en la relación con el PRI se crean mecanismos reflejados en la banda que la conducen a moderar su estructura, no por la lógica de la naturaleza conflictiva con el exterior, sino con el surgimiento de disturbios internos provocados por la deslealtad de su representante, mismo que utiliza el nacimiento de la cohesión y autoridad de la banda hacia su persona para desligarse de los objetivos de "Los Pancheros" para sacar a flote sus propios intereses.

El "Konde" no vive para la banda, sino de la banda. Sus demandas personales no son las mismas de todos; observa a la banda como una extensión de su personalidad a través "...de la introyección del fin y de la fortaleza del grupo y de la proyección de su propio yo hacia el grupo mismo...," la cree lucrativa para dar satisfacción a sus propias necesidades personales.

Esto conlleva a la creación de una meta particularizada y subjetiva que no está legitimada ética y moralmente por la banda. De esta manera, el representante de "Los Pancheros" pone en peligro el bienestar y la unidad interbanda, luego de intentar utilizarla para su beneficio propio y más en el fondo para el beneficio priista.

48 Entrevista realizada a "Los Pancheros".

49 Coser, Lewis A Las funciones... op. cit. pág. 131.

50 Op. cit. pág. 131. 
El rompimiento con el partido es inevitable ante los intereses particulares que el representante persigue y que han desviado a la banda de sus objetivos reales.

"... ahi ya se va a ver uno, o sea, ya buscas tu interés personal ¿no?, por ejemplo si te ofrecen algún acá camello ¿no? acá chido cabrón y te ofrecen un buen billete quincenalmente pus dices puta ¿ no?, pero ya sabes qué onda, que queremos que jales a todos ¿no? en apoyo acá de "x" acción ¿no? politica o como sea ¿no?, entonces aquel cabrón dice pus orita pero se dan cuenta los compas que aquel compa está manejándole chueco al grupo enton's ya valió gorro... Por eso no nos gusta aliarnos a un 'x" partido politico... "51

El status del representante comienza a ser cuestionado por transformarse en un símbolo de peligro que atenta contra la armonía de la banda. El odio hacia él se desprende por parte de sus compañeros “...sus acciones se consideran como un intento de derribar las fronteras." 52 El provoca desorden en la banda por aplicar decisiones que no están legitimadas por ella misma, creándose la duda entre los "Chavos-banda", quienes descubren su herejía por proponer "...alternativas allí donde el grupo no quiere que exista ninguna". ${ }^{33}$

Por tal motivo "Los Pancheros" cierran sus filas ante el peligro interno de la herejía. La defensa hacia la banda se convierte en el papel fundamental de los "Chavos-banda", por lo que apresuran el rompimiento con el PRI, luego de la factibilidad de perder su autonomía y quedar aglutinados, además de establecer un mecanismo que condicione el posible beneficio obtenido así como su actuar en conjunto.

Es evidente que la escisión persigue negar los nexos con el PRI, luego de que este no tiene en la mira las actividades que podrían ser de utilidad para la banda misma como lo advierten,

"Elpartido politico pus no nos entendería ¿no? porque nosotros quisiéramos que ese partido apoyara a la juventud ¿ves? porque la juventud es la que, lo que tiene ¿si? la forma de expresar es de que la juventud es la que va a luchar ¿no? y la verdad un partido politico no nos entendería porque la gente grande dijera no pus cómo nadamás a los jóvenes y nosotros lo que queremos es apoyar a los jóvenes ¿si?, te lo dice toda la banda no nadamás yo porque si un partido politico nunca nos haría caso, la verdad". ${ }^{4}$

La intimidad y la militancia de "Los Pancheros" ha dado pie por un lado a la defensa de la banda, y por otro lado a cuestionar el por qué no se alcanzaron los objetivos planteados inicialmente. Se establece una unicidad en contra de los motivos de su frustración; es decir, hacia la traición intrabanda.

51 Entrevista realizada a "Los Pancheros".

52 Coser. Lewis A. Las funciones... op. cit. pág. 79.

53 Op. cit. pág. 79.

54 Entrevista realizada a "Los Pancheros". 
La herejía del "Konde" revela para la banda los pecados por los que ha pasado, "a los miembros leales se les tranquiliza asegurándoles que el grupo en su conjunto no ha fracasado, sino únicamente algunos 'traidores'; además ahora pueden reafirmar su rectitud unificando su acción contra los 'traidores". 55

El "Konde" es transformado por la banda en "Chivo expiatorio". Su disidencia ha tendido a no favorecer los intereses de sus compañeros y lo hacen acreedor del desplazamiento de la hostilidad "pancheril" que se refuerza ante el alentador peligro que pone en incertidumbre la unidad de sus filas.

Las características de grupo cerrado y la institucionalización de su existencia por el peligro externo y/o interno, crean en la banda la purificación de sus filas, por lo que es expulsado de su seno el hereje. El "Konde" abandona a "Los Pancheros" por consenso de estos últimos.

\section{A MANERA DE CONCLUSIÓN}

La banda como espacio de poder, simbolizada por su vestimenta, lenguaje, territorio y espontaneidad cotidiana, encuentra con la música el escenario sobre el cual expresa su quehacer cotidiano, que conjunta- mente con la droga crea una liberación efímera a través de ese construir imaginario. Pese a ello la banda simboliza la unidad, una inclinación a contradecir el discurso de la "razón instrumental", ya que representa una tendencia frenética de recuperación del ocio no institucionalizada, resultando la decadencia del placer que vincula la posible pérdida de su espontaneidad cotidiana.

La decadencia del placer $^{56}$ se advierte en la banda precisamente en su "mundo de vida", misma que se relaciona con todo un sistema de "formas" de las que es creadora, pero que de ellas es moldeada en mayor o menor medida.

Evidentemente la orientación hacia el ocio estigmatizado (pobreza, desempleo, delincuencia, vagancia), la creación de una ideología consumista (asimilación positiva de valores), plasmada en la existencia social elaboran un valor profundamente negativo en oposición a las formas de consenso del discurso del ocio no institucionalizado, dejando así de ser una opción.

$\mathrm{Al}$ interior de la banda el ocio tiende oscuramente a expresar el espacio de la imaginación bajo el velo de la espontaneidad cotidiana, en contraposición de aquellos resultados fructíferos a nivel social y material. Se objetiva la fórmula institucionalizada para romper con el estigma del ocio; en consecuencia el ocio en su forma no institucionalizada (espontaneidad de la banda) llega

55 Coser, Lewis A. Las funciones... op. cit. pág. 123.

56 Ortega, Roberto Diego. “El ocio recobrado”, en Nexos. Año XI. Vol. 11, núm. 132. Diciembre de 1988. pág. 43-44. 
a presentarse como una posible opción, que a la vez se apaga porque no puede prescindir de los factores axiológicos que rigen su reproducción dentro y con la sociedad en su conjunto, creadora de su mismo cadalso. Por lo tanto la banda es consecuencia de la estructura de pobreza.

Así la banda es una alternativa consumada, sólo en el mejor de los casos se considera como un "posible" espacio donde puede llegar a limarse ciertas asperezas de la cotidianidad alineada. 